\title{
A Cost Effective Automatic Balloon Launcher
}

Submitted to:

Dr. Michael Huesemann, Ph.D

Staff Research Engineer and SBIR Progam Manager

Pacific Northwest National Laboratory

Sequim, WA 98382

Application Number 55120-99-1

Submitted by:

Visidyne, Inc.

10 Corporate Place

South Bedford Street

Burlington, MA 01803

Tele: (781) 273-2820

Fax: (781) 272-1068

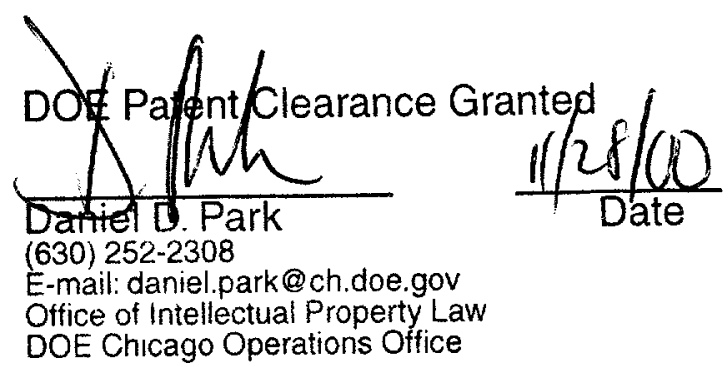




\section{DISCLAIMER}

This report was prepared as an account of work sponsored by an agency of the United States Government. Neither the United States Government nor any agency thereof, nor any of their employees, make any warranty, express or implied, or assumes any legal liability or responsibility for the accuracy, completeness, or usefulness of any information, apparatus, product, or process disclosed, or represents that its use would not infringe privately owned rights. Reference herein to any specific commercial product, process, or service by trade name, trademark, manufacturer, or otherwise does not necessarily constitute or imply its endorsement, recommendation, or favoring by the United States Government or any agency thereof. The views and opinions of authors expressed herein do not necessarily state or reflect those of the United States Government or any agency thereof. 


\section{DISCLAIMER}

Portions of this document may be illegible in electronic image products. Images are produced from the best available original document. 


\section{Table of Contents}

Section

PROJECT SUMMARY

1 PROJECT OBJECTIVES

2 WORK CARRIED OUT

2.1 Radiosondes

2.2 Radiosonde Batteries

2.3 Flight Trains

2.4 Antennas

2.5 Shelter

2.6 Radiosonde Canister

2.7 Operating Environment

2.8 Ambient Conditions Monitoring

2.9 Consumables

2.10 Site Requirements

2.11 Safety

2.12 Computer and Software

3 DEGREE OF WHICH PHASE I HAS DEMONSTRATE TECHNICAL FEASIBILITY

3.1 Critical Components List

$4 \quad$ RESULTS

5 ECONOMIC FEASIBILITY

6 PHASE II TECHNICAL OBJECTIVES

7 PHASE II WORK PLAN

7.1 Introduction

8 OPTIONAL PHASE II COMMITMENT (COST SHARING)

\section{APPENDICES}

A Letter of Commitment for Sippican to Visidyne for Phase II Cost Sharing

B Cost Proposal from Sippican for Phase II Cost Sharing

C Letter from Air Force Research Laboratory

D Letter from Space Data Corporation

E Phase I Grant Application, "A Cost Effective Automatic Balloon Launcher" (VI-3511) 


\section{LIST OF FIGURES}

$\underline{\text { Figure }}$

1 Voltage versus time after activation (immersion in water) for two typical radiosonde batteries. One battery was wetted manually, the other by the Automatic mechanism proposed for use in Visidyne's Automatic Radiosonde Launcher

$2 \quad$ Single Sonde and Balloon Layout

3 Sonde Battery Fill Mechanism

4 Autosonde Launcher Shelter

$5 \quad$ Sonde Canister

6 Multiple Sonde, Layout

$7 \quad$ Working Lab Model 


\section{PROJECT SUMMARY}

\section{Purpose of Research}

Approximately 800,000 balloon-borne radiosondes are hand-launched each year, a cost and labor-intensive procedure. Development of a low-cost Automatic Radiosonde Launcher would allow the manual procedure to be replaced with a reliable and less expensive process.

Balloon-borne radiosondes provide essential meteorological data used by forecasters and researchers around the globe. The National Weather service alone launches tens of thousands of sondes from sites across the US. Although worldwide launching of radiosondes has been done for many years ${ }^{[1]}$, it remains a labor intensive and therefore expensive operation.

Using its own funding and, more recently with the help of a Phase I SBIR grant, Visidyne, Inc. has begun investigating the feasibility of building an Automatic Radiosonde Launcher (ARL) that can be built at a cost that will be acceptable to the commercial marketplace. That work has led to the issuing of four patents ${ }^{[3-6]}$ covering important innovations that will allow us to meet that goal. Under the recent Phase I effort, solutions to many of the key problems have been tested in the laboratory an in real-world demonstrations in the field.

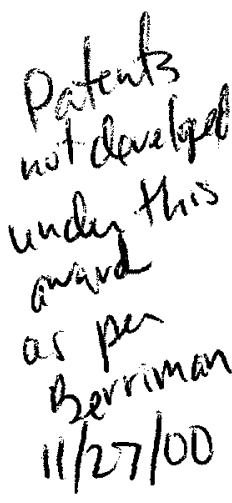

$\underline{\text { Results }}$

The balloon filling, battery wetting, and launch release mechanisms were designed, built, and tested. A breadboard launcher was constructed and tested to prove feasibility of key system elements. Demonstration launches of radiosondes were performed using the breadboard launcher from the National Weather Service facility in Gray, ME, and from Hanscom AFB in Lexington, MA. The cost and size of a full scale shelter prevented us from building one during Phase I, however, we do have a design that will accomplish our goals. See Figure 4.

The Automatic Radiosonde Launcher will significantly reduce the cost of launching balloon-borne instruments. US and foreign weather services and atmospheric, climatological, and meteorological researchers will all benefit from this innovation. 


\section{PROJECT OBJECTIVES}

\subsection{Technical Approach}

There are many problems that must be addressed by any proposed design of an automatic radiosonde launcher. In the course of our research, we have, we believe, identified the salient issues and developed practical solutions to address them. Our approach has been to break down the overall task into a set of (relatively) independent processes. Each process is then analyzed and reduced to define the minimal set of design requirement for that segment of the system. Controlling cost and ensuring reliability by emphasizing simplicity in design has been the driving philosophy throughout. The goal is to design a practical system, not a "mechanical marvel" that only exchanges labor hours spent launching sondes for labor hours spent maintaining equipment. The issues addressed by Visidyne's proposed automatic radiosonde balloon launcher are detailed in the sections below.

Our basic philosophy in approaching the design is to mimic as much as possible standard practices currently used for manual launches. This is desirable for two reasons. First, techniques and procedures for launching balloon borne radiosondes have been developed over many years that are highly reliable and yield good, consistent results. It is prudent to take advantage of this experience to whatever extent possible. Second, the customers for the system, weather services and atmospheric researchers, tend to be conservative in nature. They are always concerned that changes, however innocuous they may appear, may impact the reliability of their measurements and the quality of the data. The more the automated process resembles the tried-and-true manual process, the more quickly and easily it will be received by the marketplace.

\section{WORK CARRIED OUT}

\subsection{Radiosondes}

From the perspective of the user, the radiosonde is the most important component of the system. It is imperative that automating the launch process in no way compromises the integrity of the sonde. Each sonde must be handled in such a way that it maintains its factory calibration. 
That calibration must be verified before launch by comparing sonde data to independently measured temperature, pressure and humidity, a process known as "baselining".

Radiosondes typically come from the factory in a hermetically sealed bag. This is done to ensure that ambient storage conditions do not change the calibration of the sonde's sensors (particularly the humidity sensors). Sondes remain in their sealed packages until an hour or so before launch. An automated system that stores multiple sondes for several days must take measures to ensure that their calibrations are not compromised in storage.

With each carton of sondes shipped to a user, on several sonde models, the manufacturer includes a computer diskette with calibration data. The calibration data is copied from the diskette into the user's personal computer when a new box of sondes is unpacked. The sondes are identified by unique serial numbers so that each one can be matched with the correct calibration data file. Prior to launching a sonde, the technician reads the serial number off the sonde or its package and keys it into the computer manually. This assures that the correct calibration correction factors will be applied to the data from a particular radiosonde. Alternately, some sonde manufacturers have begun encoding calibration and serialization data in the sonde's data stream so that it is continuously transmitted to the receiving station on the ground along with the sensor readings. Regardless of which technique is used, an automated launcher must support procedures to collect and store sonde calibration data and maintain serialization so the user knows exactly what sonde is selected for any given launch.

A feature that is highly desirable for an automated launcher is the ability to use different types of sondes from different manufacturers. The ideal launcher will adapt easily to accommodate the form factors of most existing sondes, and require little or no modification to the sonde itself. This is a weakness of many concepts we have studied. Intricate loading mechanisms or cassettes often impose tight restrictions on the size and shape of the sondes. We will present our solution to this problem in subsequent sections of this proposal.

One feature that distinguishes different sondes is the method employed to track them during flight. The oldest technique, which is still used in many locations, is to use a radiotheodolite. A radiotheodolite consists of a directional antenna on a mechanical mount that moves the antenna in azimuth and elevation. The antenna receives the transmitted signal from the sonde, and a servo controller points the antenna to get the maximum signal strength. The 
antenna therefore tracks the sonde and the controller records the azimuth and elevation angles as a function of time. When combined with altitude data, determined by the sonde's pressure sensor and telemetered back along with temperature and relative humidity, range to the sonde can be determined by triangulation.

Other radiosondes use Loran-C or, most recently, GPS to determine location in flight. These sondes have receivers that acquire the navigation signals from either the Loran-C network or GPS satellites, determine their position in three dimensional space from those signals, and insert the positional data in the data stream. The newer Loran-C and GPS sondes are more accurate than radiotheodolites and do not require a mechanically-steered antenna. Signals are received by an array of directional antennas configured to give complete omnidirectional coverage. A multiplexer automatically selects the antenna element with the strongest signal and routs it to the receiver and data recorder. While the sondes themselves are slightly more expensive than those used with a radiotheodolite ground station, the ground station is simpler and cheaper and the performance in determining position superior.

Of the three tracking technologies, radiotheodolite is the least amenable to automated launch. If the sonde signal is not acquired by the tracking antenna right after launch, it may never be received and the valuable data lost. Tracking is most difficult in the first seconds after release because the angular rates in azimuth and elevation change most rapidly when range is smallest. During manual launches, the antenna is pre-positioned based on the wind speed and direction prior to balloon release to help it acquire. Even so, it is not unusual for swirling or unpredictable gusts to carry the sonde along a path that does not intersect the antenna line-of-sight. Often the technician must take manual control of the antenna pointing to acquire and track the signal until the radiotheodolite has locked on and the balloon is far enough away to be tracked automatically.

A radiotheodolite used in conjunction with an automated launcher must have better signal acquisition performance than we have seen demonstrated in manual launches. Without either better radiotheodolite tracking performance in the early phases of flight, or a complimentary sensor (e.g. a video tracker) to aid in signal acquisition operator intervention is necessary to guarantee that the radiosonde signal is successfully acquired.

Marketing considerations may alleviate the need to solve this potentially thorny problem. Almost universally, radiotheodolite tracking is being gradually replaced by Loran-C and GPS. 
The US Weather Service has in fact committed to a Radiosonde Replacement Program, which will upgrade all of their facilities to use GPS sondes exclusively. Given the shrinking base of radiotheodolite installations, the market's overwhelming preference for the other technologies for new or upgraded facilities, and the extra cost to develop and build a radiotheodolite-compatible launcher, the decision not to support radiotheodolite may be the most prudent.

\subsection{Radiosonde Batteries}

Radiosondes have traditionally used water-activated batteries because of their high power density and tolerance for low temperature (due to self-heating). Prior to launch, the technician removes the battery from its sealed package and immerses it in tap water for about three minutes. It is then removed from the water and connected to a tester that measures its output voltage under load. The battery output voltage will climb to a predetermined minimum within a few minutes after activation. Failure to reach the minimum voltage indicates a defective battery. Radiosonde battery voltage typically continues to climb for about an hour after activation, and the output remains sufficient to power a sonde for 2 to 2.25 hours. If the battery is defective, an automated launcher must detect the failure and adjust as the technician would by preparing another battery. Launching a sonde with an under performing battery is not acceptable. A weak battery is likely to outlast the launch window (1 hour typically) to send up a replacement, but not long enough to yield useful data.

The automated launcher must be able to activate the battery by filling it with water and verify that its output has met minimum voltage-under-load requirements. It must then connect the battery to the sonde, or else make provision for the battery to be connected before wetting. If the battery is connected to the sonde before wetting, provision must be made to ensure that the slow voltage rise does not cause the sonde's electronics to hang up, a known problem with some sondes $^{[7]}$.

The batteries, like the radiosondes themselves, are shipped from the factory in sealed bags to prevent degradation in storage primarily due to humidity. The automatic launcher design must provide a similar controlled storage environment to keep the batteries safe until use.

\subsection{Flight Trains}


The flight train consists of all the things trailing behind and beneath the balloon in addition to the sonde. Immediately beneath the balloon is a long leader-line. This line, usually of cotton twine, is made 20 to 30 meters long to assure that the sonde lags far enough below that its measurements are not disturbed by the balloon. Sometimes, this line is wound on a dereeler. When so equipped, the leader is initially wound on a spool and gradually paid-out by the dereeler mechanism as the balloon rises. This is done to prevent the sonde from snagging on trees or tall buildings around the launch site by keeping the leader short until the balloon and sonde have risen out of danger. Below the leader are a parachute, the radiosonde itself, and optionally a chemical light stick for nighttime radiotheodolite flights. The light stick aids in visually tracking the balloon during night launches. This helps the technician manually steer the radiotheodolite antenna to acquire the sonde signal. The radiosonde may also trail a thin wire antenna for LoranC reception.

The automatic launcher will have to accommodate the traditional flight train as described above with the possible exception of the light stick (since this is used for radiotheodolite operations only and there will be no operator around to see it anyway).

\subsection{Antennas}

Antennas and receiver electronics will have to be provided to receive the radiosonde signal after launch. In addition, since it is necessary to receive the radiosonde signals before release to verify calibration and correct operation, an additional antenna may be needed inside the shelter.

\section{$2.5 \underline{\text { Shelter }}$}

The shelter is an integral part of the automatic radiosonde balloon launcher. Balloons and sondes must be kept out of rain, snow, wind, etc. while waiting to be launched. Obviously, it will be necessary for the balloons, radiosondes, and support equipment to be protected from the weather. Balloons must also be shielded from wind when they are being filled. Visidyne's Phase I experiments have shown us that the balloon is most vulnerable to damage when it is partially inflated. 
Means must be provided for the balloon to exit the shelter. This can be accomplished any number of ways, but the simplest (and probably the best) is to provide a large hatch or door on the roof of the shelter through which the balloon can rise. This hatch must be weather tight, capable of handling reasonable snow loads, and can have no features that could become a puncture hazard to the balloons or snag the trailing sonde or flight train. At the balloon launch enclosure designed by the University Corporation for Atmospheric Research at the National Weather Service station in Albany, NY, balloons and sondes snagging on features in the hatch opening is a problem that limits the utility of the facility ${ }^{[8]}$. Equipment (e.g., electronics) inside the shelter must be "drip-proof". That is, it must be protected from rain or snow damage for equipment when hatch is opened, even though the hatch is likely to be open only long enough to eject the sonde.

Optionally, it may be desirable for the facility to support manual operation. No matter how well the launcher and shelter are designed, there may be some unusual conditions or circumstances which demand that balloons be launched manually. Adding a side door large enough for an inflated balloon to pass through would allow an operator to prepare the balloon and sonde inside, then carry it out for manual release. Some market research would be required to find out how important this is to the typical customer.

\subsection{Radiosonde Canister}

Within the automatic launcher, eight or more radiosondes will be loaded and stored for four days or more. Current practice calls for the sondes to remain in air-tight factory sealed foil bags until an hour or so before launch. While its entirely possible that being outside the bag for longer than a few hours before launch is not detrimental to the sonde's sensors or their calibration, to our knowledge no research has been done to support this. Furthermore, such research is beyond the scope of our automatic launcher development effort. To be accepted by the market, we believe that the automatic launcher must provide protection for the sondes awaiting launch from temperature and humidity extremes that is equivalent to the factory packaging. We feel that to do this, the radiosondes must be stored in a hermetically sealed compartment or canister. The servicing technician would remove the sondes from their bags and place them in the canister. The canister would then be backfilled with a clean, dry gas (nitrogen 
or dry air) or evacuated with a vacuum pump. The inside of the canister would also be heated to maintain moderate storage temperatures as necessary.

The radiosondes would remain in the protective environment provided by the canister until just prior to launch. During the prelaunch sequence, a ventilator would draw ambient air into the canister to acclimate the sonde to outside ambient temperature and humidity as part of the sonde baselining procedure.

\subsection{Operating Environment}

The automatic launcher will be required to operate at temperature extremes from summer in Miami to winter in Minnesota. All equipment associated with the launcher must operate over these extremes, or the shelter must protect them form the extremes by providing active heating or cooling. This might be accomplished by heating or cooling only the sensitive components rather than the entire shelter. For example, water is required for battery activation and this water must be at a moderate temperature at the time of activation for proper battery operation. This might be done by heating the reservoir tank and plumbing, rather than by heating the whole sheiter.

To be useful, the launcher must be able to operate in windy conditions. We have (rather arbitrarily) taken 30 knots as the requirement. This would make the launcher useable in most locations on all but a few days a year.

\subsection{Ambient Conditions Monitoring}

The launcher should be equipped with a means to determine surface wind direction and velocity, pressure, temperature, and humidity. Wind direction and velocity would be used by the launcher's computer to make a go/no-go decision on launching and to predict the track of the balloon. Temperature, pressure and humidity data would be used for baselining the sonde and is used as the initial measurement point for the radiosonde observation reports.

It may not be necessary for the launcher to have its own meteorological instruments if, for example, the computer is networked to the weather station's computers and can obtain the necessary information electronically. 


\subsection{Consumables}

Storage and handling systems must be provided for water (for battery activation), lift gas (hydrogen or helium), and compressed air (for mechanical actuators). Quantity must be sufficient to launch a full load (nominally eight) of balloons without reloading. Precautions must be taken to protect the consumables from the environment. For example, water stores cannot be allowed to freeze.

\subsection{Site Requirements}

The launcher should be suitable for installation at any location where balloons are currently released manually. It should be designed not to preclude rooftop installations, desirable in some locations.

A general requirement which applies to both manual and automated launch sites is that the surrounding area be free of tall obstructions. The presence of tall trees, buildings, power lines, communications towers, etc. limit the maximum wind velocity for safe balloon release.

For the automatic launcher, we will assume that $\mathrm{AC}$ electric power is available at the site and that some means of hard-wired communication for the control computer can be provided. This could be either an Ethernet link to a nearby LAN or telephone lines for a modem hook up. At remote sites where utility power and telephone are not available, a generator and wireless communications link could be provided for an additional cost. Because remote-site operation without utility power and communications infrastructure is not a central issue, we will not make that a requirement of the Phase II effort.

\subsection{Safety}

The automatic launcher will be designed to meet all applicable regulatory requirements and standards such as Underwriters Laboratories (UL), CSA, VDE, etc.

Safety of unauthorized persons, for example mischievous children or vandals, must be provided for, especially when the launcher is sited in an area where access cannot be easily restricted. If the launcher is not on a rooftop or other generally inaccessible location, it should be surrounded by a secure fence such as those surrounding unmanned electric and natural gas utility 
facilities. Warning signs must be posted. In addition, care must be taken in the design to minimize the risk of injury from moving parts external to the structure such as the roof hatch mechanisms. Moving parts should be enclosed where possible. In the case of the roof hatch, safety mechanisms such as those used on garage door openers must be used to prevent the door from closing on and crushing a person. Even the risk to life and limb of an unauthorized person who climbed onto the roof must be considered. Every possible step should be taken to reduce the likelihood that an unauthorized climber can fall or be ejected from the roof when it operates.

Unauthorized entry into the shelter interior is obviously undesirable from both a safety and a security perspective. An alarm system to detect and deter intruders may be necessary to prevent this.

All of these safety and liability issues must be addressed in one way or another before the system can be sold commercially. Identifying safety requirements up front will promote a safer design from the start and reduce the effort spent on "band-aid" fixes later on.

\subsection{Computer and Software}

The automatic radiosonde launcher will have a computer that:

- Schedules launches

- Provide automated control of all actuators and mechanisms

- Controls launch processes (battery and balloon filling, sonde baselining, etc.)

- Provides a local operator interface (e.g. keyboard and monitor)

- Provides capability for a remote operator interface (e.g., via modem or Ethernet)

- Provide means to read cal data and maintain sonde serial number records.

- Interface to data gathering system (sonde receiver)

The computer must be rugged enough to withstand the environment inside the shelter (especially if the shelter is not climate controlled). It should be housed so that it cannot become a source of ignition when hydrogen is used.

The system software will be an important component of the final system. Correctly assessing the needs of the customer and addressing them with reliable, user-friendly, state of the art software is an important part of the design. 


\section{DEGREE TO WHICH PHASE I HAS DEMONSTRATED TECHNICAL EASIBILITY}

\subsection{Critical Components List}

\section{Battery Filling}

The mechanism for wetting of the water-activated battery is an important component of the system. Several different approaches to the problem were examined or tested during Phase I. Some of the different methods we tried for automatic filling of the battery were:

1. Using the hermetically sealed package that comes with the sonde to hold the water,

2. Using gravity feed from an internal supply into the battery box,

3. Using water under pressure to fill a battery box,

4. A battery with its own separate water supply, and

5. Using a vacuum to pull the water into battery box and allow excess to drain off.

Laboratory testing showed that each method had strengths and weaknesses. The vacuum technique proved to be the most successful, and was incorporated into the breadboard system design.

To properly activate the battery, it should be immersed for three minutes, then drained of excess water. Using a vacuum pump allows water to be drawn into the battery box until it is full. Water is held in the battery box as long as vacuum is maintained. After the specified soak period, the vacuum pump is switched off and excess water drains away. This system for battery activation is very simple, does an excellent job of wetting the battery, is reliable and inexpensive to implement.

\section{$\underline{\text { Battery Activation Test }}$}

The battery activation technique using a vacuum pump to draw water into the battery compartment and hold it for a predetermined soak time (nominally 3 minutes) appeared to work well. The batteries are wetted by immersion, much as in the manual process. Excess water is then allowed to drain away when the vacuum is switched off. 
To assure that batteries wetted by the automatic system perform as well as their carefully hand-prepared counterparts, a head-to-head comparison was performed. Two batteries from Vaisala radiosondes Model No. RS80-15L were used in the comparison. The batteries were wetted, then an electrical load roughly equivalent to the RS80-15L (200 ohms) was applied and the battery output voltage measured as a function of time. The results are shown in Figure 1 below.

$00-160$

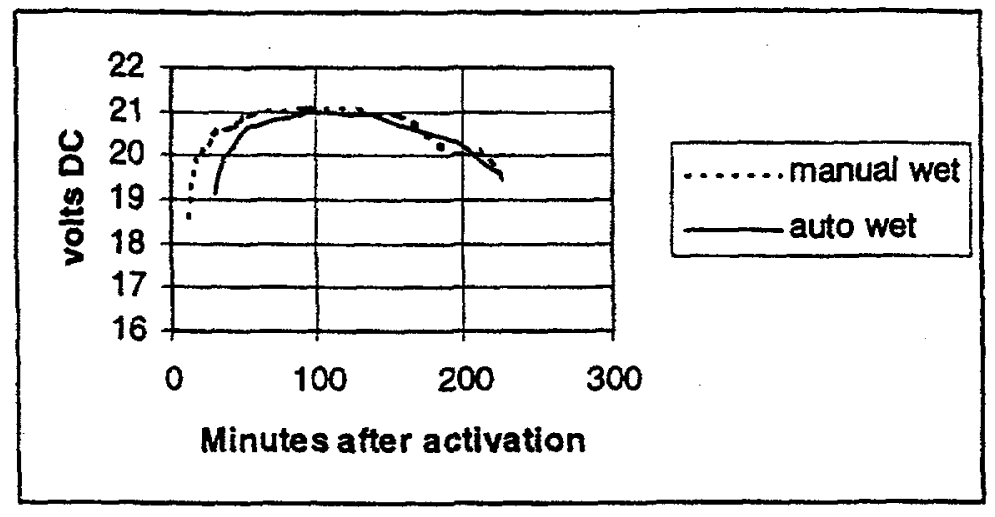

Figure 1. Voltage versus time after activation (immersion in water) for two typical radiosonde batteries. One battery was wetted manually, the other by the automatic mechanism proposed for use in Visidyne's Automatic Radiosonde Launcher.

There is no significant difference in electrical performance between the two test units wetted by the different methods. In addition to the electrical measurements, the batteries were each weighed immediately before and after activation to see if there was any different in the amount of water absorbed by the cells. The water absorbed for the manual and automatic wetting procedures was 40.0 grams and 42.1 grams, respectively. From these measurements, we conclude that the method for automatic battery activation devised by Visidyne is equally as effective as the traditional manual method.

\section{Sonde Conditioning}

To assure that the sonde is conditioned to the outside ambient environment, means must be provided to flush the hermetically-sealed canister in which the sonde is stored with outside air. 
With the sonde sitting in the canister, the canister cover opens after battery activation. First, we tried using a small fan inside the canister. We felt that the air flow obtained this way was insufficient, so a four inch diameter opening was added, with ductwork to channel outside air directly to the sonde canister. This was very fast and efficient in conditioning the sonde. While this approach necessitates a second hermetically sealed door or valve to keep the ventilation opening closed during storage, we feel that the additional complexity is warranted, given the importance of acclimating this sonde to the outside environment, rather than to the environment of the hermetically sealed canister.

\section{Balloon Filling and Deployment}

Storing the balloon in the canister prior to filling would work only for the smaller diameter balloons. The balloon manufacture states that at low temperature, balloons must be preheated before filling. Different folding and heating techniques were tried for various size balloons from 300 grams to 1200 grams. Folding became complicated and labor intensive and preheated balloon boxes started taking up large amounts of real estate. From the weather stations we visited, we saw that in manual launches balloons are first laid full-length. This method is still the fastest and simplest for a technician loading the launcher for all balloon sizes. We have decided that the best approach is to mimic the manual procedure. Rather than fold the balloon up into a compact package, the servicing technician will lay the balloon in a semicircular balloon tray. (See Figure 2). To reduce the footprint, we added a 90 degree bend in the balloon tray. A fold away electric blanket is provided to keep the balloon temperature moderate during storage and filling. This method works for all balloon sizes. Each balloon will have its own quick release valve attached and ready for insertion. We designed one that uses an O-ring over the outside of the balloon neck as a fastening band. 


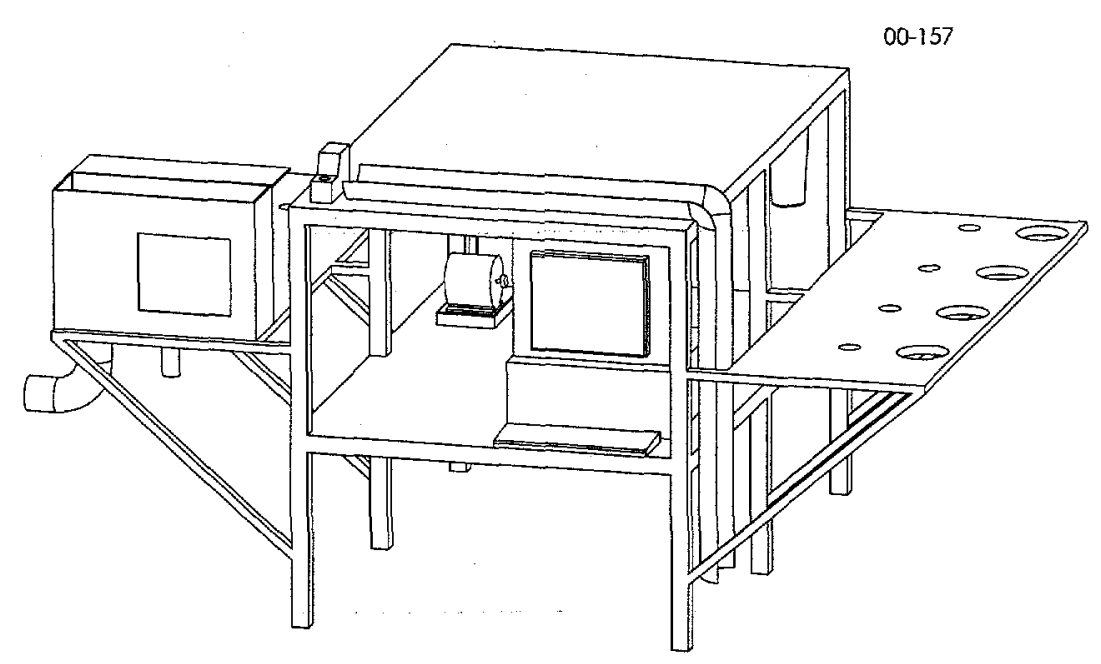

Figure 2. Single Sonde and Balloon Layout

\section{Signal Acquisition and Tracking}

During field trials at Gray, ME weather station (using a radiotheodolite ground station) and Hanscom AFB (using a Loran-C ground station), we picked up the signal from the radiosonde after battery filling and before launch using equipment on site. However, the signal was lost shortly after launch at the Gray, ME facility. We think this was due to a switch problem that was later corrected. At Hanscom AFB the signal was tracked and continued after launch and data was recorded without any problems.

\section{Balloon Size Capacity}

Because of the chosen method of balloon filling and deployment, we can accommodate any size balloon from 100 grams to 1200 grams without modification. Since the balloons are not folded tightly to fit into a canister, the fill mechanism is indifferent to balloon size. Rather than balloons size being constrained by the loading or fill mechanism, it is constrained only by the size of the hatch opening in the roof of the shelter.

\section{Flight Train Types}

Parachutes and dereelers come in different sizes depending on payload size and sonde type. Various storage methods were tried with different size dereelers and parachutes and again the method that required the least amount of labor was selected. Complicated fold up devices 
that we tested proved to be unreliable. We determined that the flight train should be stored in an area adjacent to each balloon.

We found that the best method was to simply lay the flight train components along side the balloon, taking care to protect the balloon from the metal parts such as the dereeler.

\section{Maintain Sonde Calibration}

Once radiosondes are removed from their protective packaging and loaded into an auto launcher, they must be protected from the elements, mainly moisture. To do this, we back-filled the hermetically sealed container with dry nitrogen.

\section{Computer Software}

During lab and field test we used software that Visidyne programmed to run all of the critical functions of the auto launcher. After some debugging, lab and field test performed without a problem.

\section{Sonde Modifications Required}

To switch from manual to auto launch, the radiosonde will have to be reworked to accept the new battery box assembly. This could be performed in-house, or delivered with the new batteries in place. For our lab and field test we reworked existing sondes without a problem. The sonde manufacturer will do this for production units. (See Figure 3). 


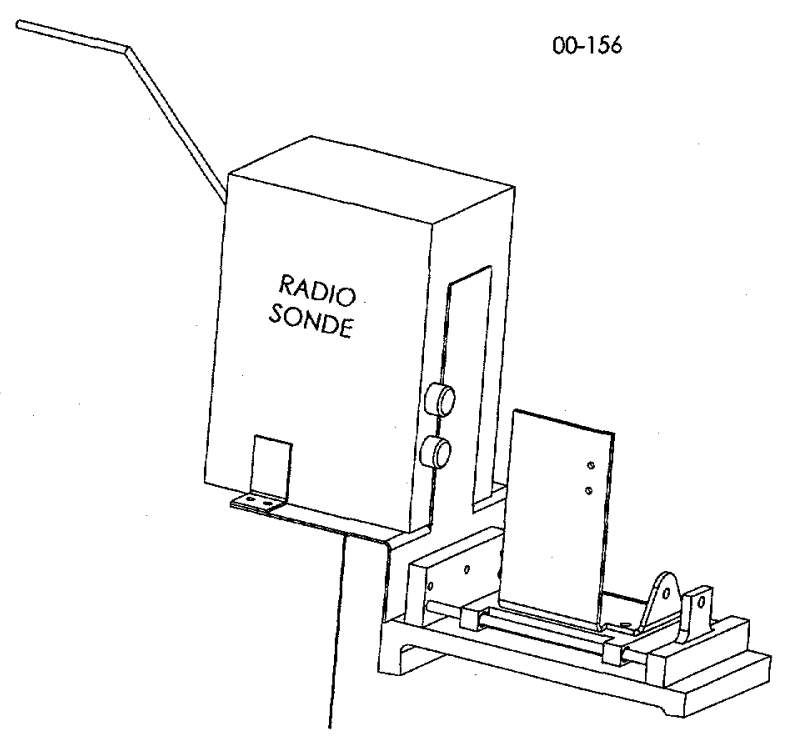

Figure 3. Sonde Battery Fill Mechanism

\section{Shelter Requirements}

The cost and size of a full scale shelter prevented us from building one during Phase I, however, we do have a design that will accomplish our goals. See Figure 4. 


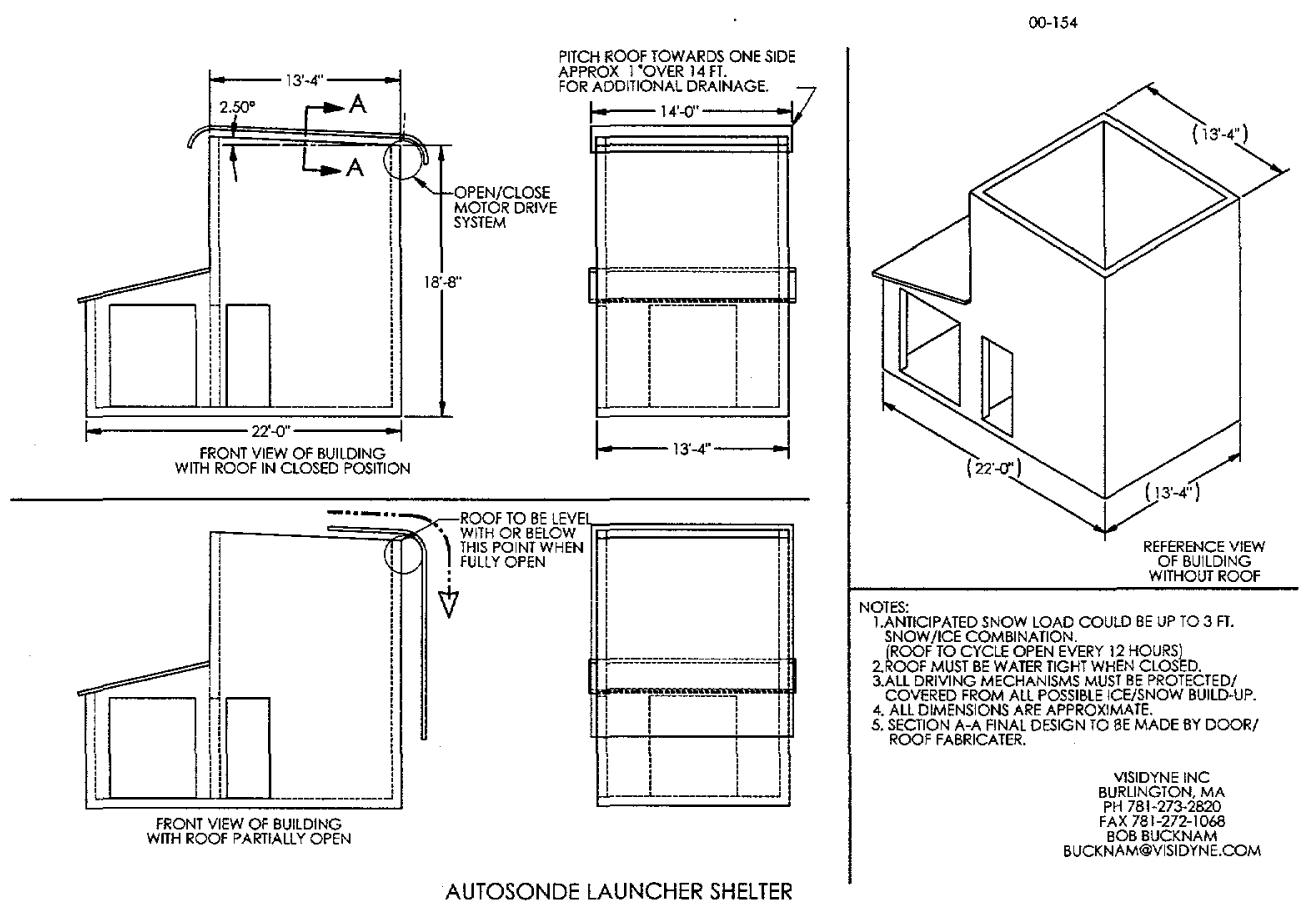

Figure 4. Autosonde Launcher Shelter

The shelter itself is relatively simple. The main area is covered by a retractable, weather tight steel hatch. The hatch is essentially a steel garage door. Commercially available units are rated for forces of up to $40 \mathrm{lbs} / \mathrm{ft}^{2}$. This translates to about eight inches of water, or about 72 inches of snow.

This hatch design will be very inexpensive and reliable. An over hang on the leading edge (left side of Figure 4) will prevent snow build up from falling into the shelter as the hatch opens. Also, the snow load is jettisoned when the door opens, thus reducing the maximum load that the hatch must support. In heavy snowfall, the hatch could be cycled periodically to relieve the snow load.

Water tight sealing of the hatch has also been considered. Since these doors are deigned primarily for vertical installations, the manufacturers we talked to guarantee water-tight performance in that orientation only. While they may work fine horizontally, if leakage is found to be a problem it can be solved by adding a flexible rubber membrane on top of the hatch.

\section{Breadboard Hardware and Lab Test}


Breadboard hardware for all the critical components was built and reworked many times during Phase I. Field trials were conducted and additional rework performed. The last field test proved the technical feasibility of the project.

\section{Accommodate Various Sonde Configurations}

Switching from a Vaisala sonde to a Sippican mark II MICROSONDE required only minor changes to the sonde platform, changing battery sizes did not change the filling procedure. The system can handle either type of sonde without major changes. (See Figure 5).

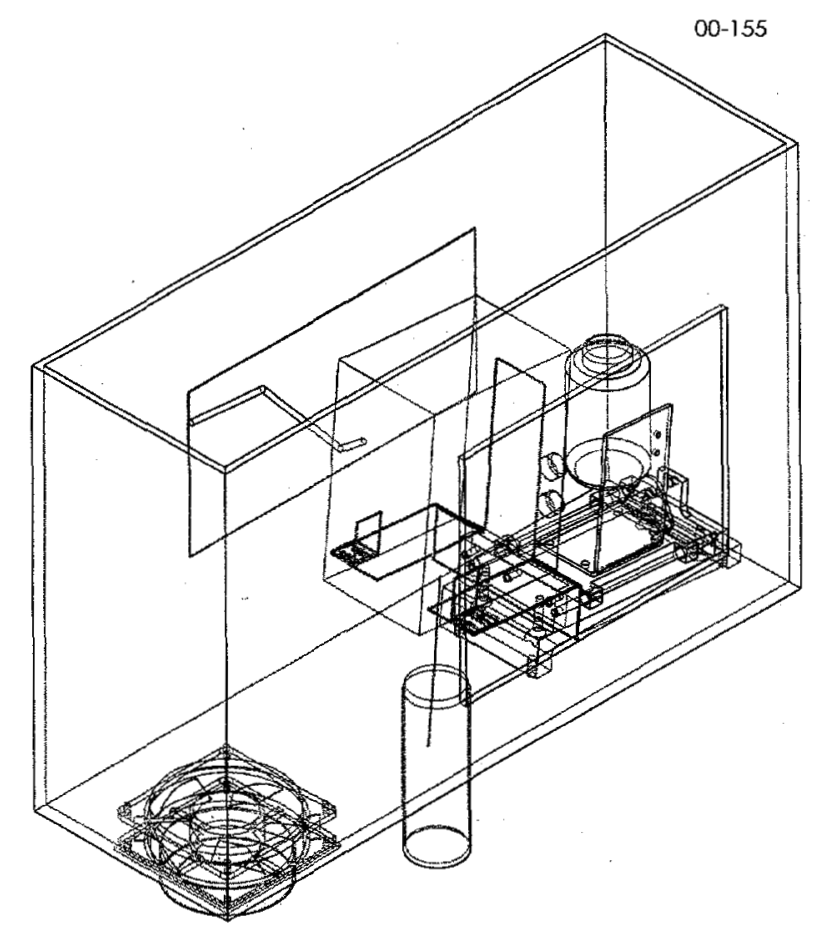

Figure 5. Sonde Canister

\section{Operates Under Most Weather Conditions}

During launch the shelter hatch is only open for one to two minutes. Snow or rain will not have an impact on any of the system components. Field test will determine the maximum wind velocity and weather conditions that will still permit a launch. During our second field test at Hanscom AFB, and without the protection of a shelter, wind gusts up to $20 \mathrm{mph}$ were not a problem. 


\section{Easy to Preload and Service}

Loading the auto launcher is easier than the manual procedure being used today. The balloon just plugs in, there is no waiting for the battery, launch time is no longer an issue, and the shelter can be serviced during slow periods. (See Figures 6 and 7).

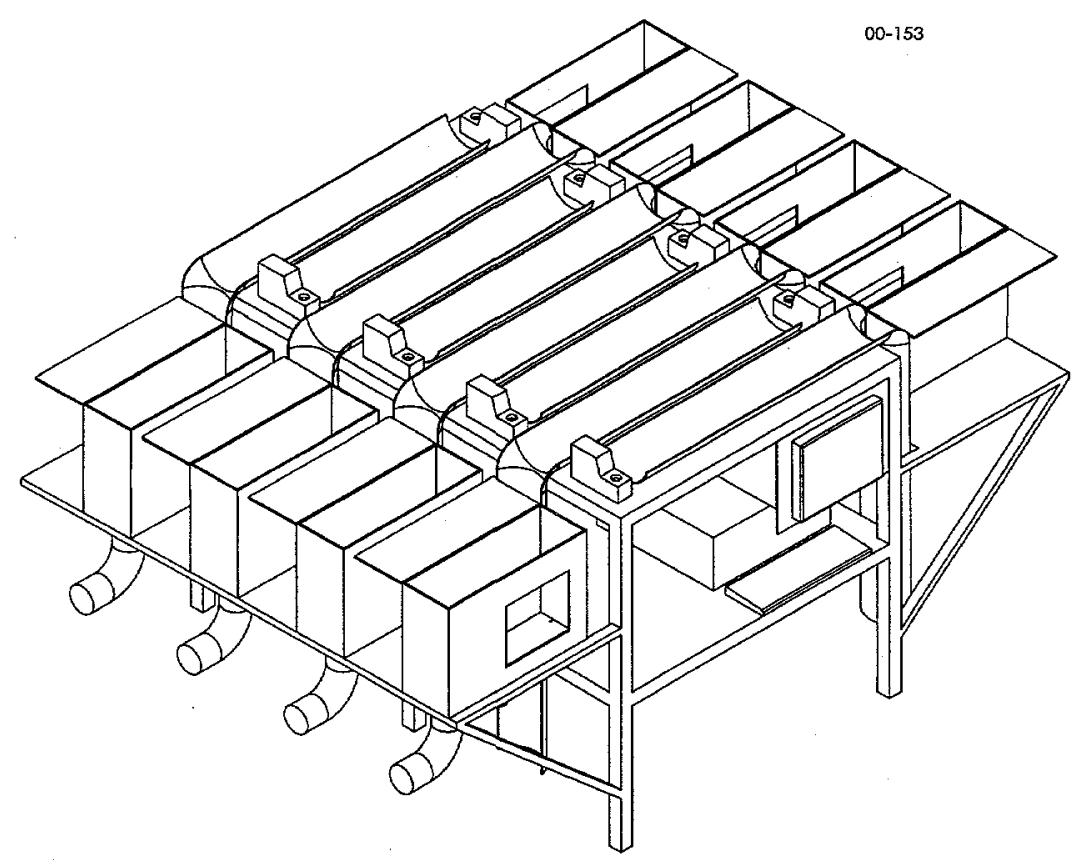

Figure 6. Multiple Sonde, Layout 
00-151
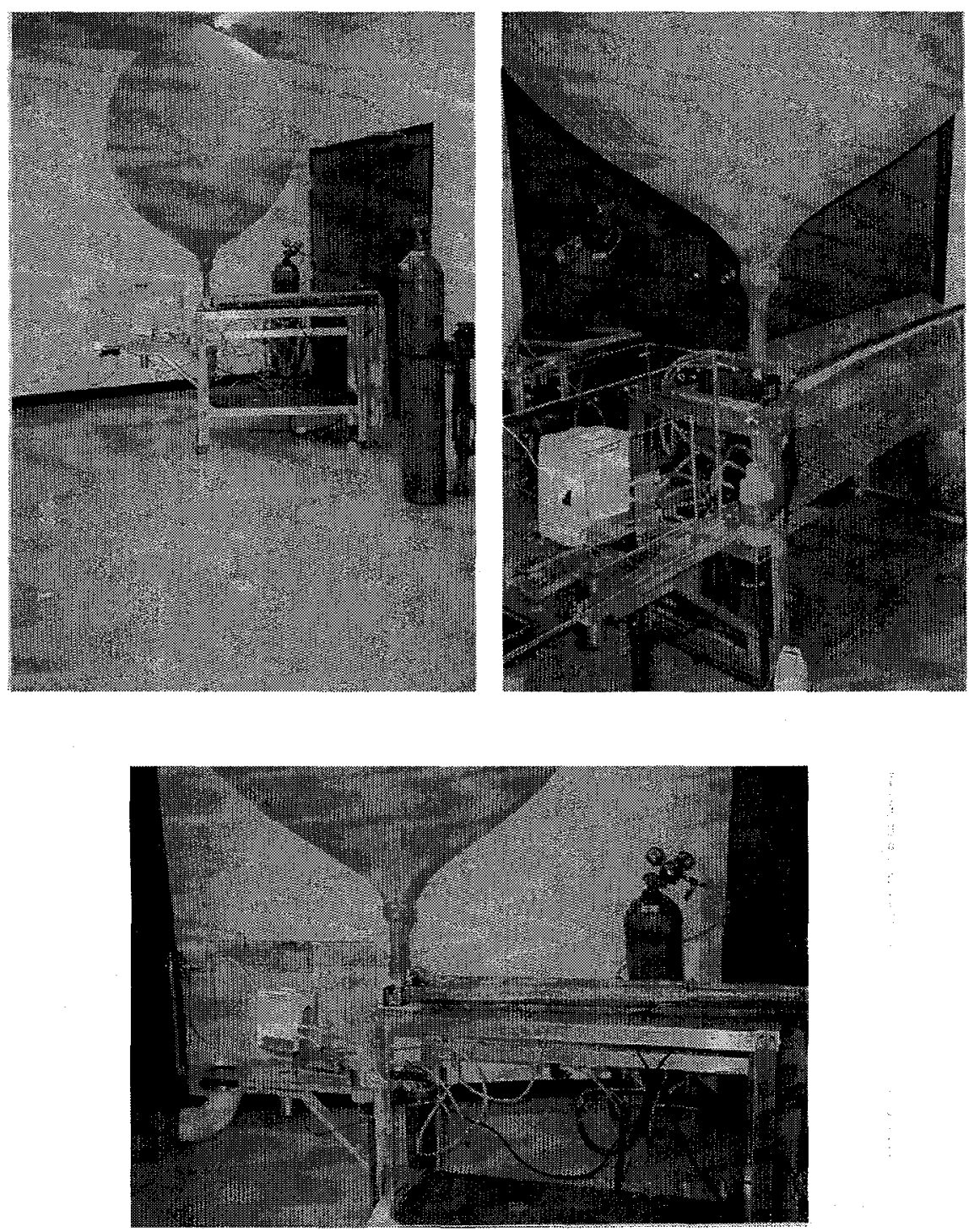

Figure 7. Working Lab Model

\section{$\underline{\text { Reliability }}$}

The critical components have been cycled many times during lab test and continued to operate as programmed without faults. 


\section{RESULTS}

The balloon filling, battery wetting, and launch release mechanisms were designed, built, and tested. A breadboard launcher was constructed and tested to prove feasibility of key system elements. Demonstration launches of radiosondes were performed using the breadboard launcher from the National Weather Service facility in Gray, ME, and from Hanscom AFB in Lexington, MA. The cost and size of a full scale shelter prevented us from building one during Phase I, however, we do have a design that will accomplish our goals. See Figure 4.

The Automatic Radiosonde Launcher will significantly reduce the cost of launching balloon-borne instruments. US and foreign weather services and atmospheric, climatological, and meteorological researchers will all benefit from this innovation.

\section{ECONOMIC FEASIBILITY}

A major anticipated economic benefit of an Automatic Radiosonde Launcher (ARL) is the savings in the annual operating cost. Radiosonde users in countries where labor cost is relatively high have recently started to evaluate total operating costs, as opposed to simply the costs of the consumables. The proposed ARL would require only periodic servicing by a single radiosonde technician. For a site having a year-round launching schedule the installation of an ARL would yield a savings equal to the projected purchase price within the first year of operation. This cost benefit would result in accelerated demand by other users of radiosondes such as the National Weather Service, Environmental Canada, and other national and international organizations.

There will also be a significant scientific advantage to automated launching with the ARL sonde launcher since it can be targeted for specific meteorological conditions of interest whenever they occur. These conditions could include front passages, storms, or synchronous launching with a specific experiment. The cost advantage of the ARL could also be applied to the acquisition of more data.

Balloon-borne radiosondes will be of value in weather predictions for the foreseeable future. Satellite and groundbased data might eventually replace them, but the well-known fact is that the properties of various atmospheric layers play vital roles in our weather. ${ }^{[9]}$ This 
information cannot be readily determined by any means other than in-situ observations with radiosondes, and meteorologists are requesting data on finer microscales in order to improve their weather predictions. ${ }^{[10]}$

During severe weather conditions, or during off-hour observations, present radiosonde launch facilities are not prepared to launch additional sondes without added manpower, lead time, and expense. Automated sonde launchers are ready to launch anytime, without advanced notice or preparations. The availability of additional observations when required would improve the accuracy of weather predictions during difficult conditions. Special projects could also be performed under various conditions.

Benefits will accrue to Visidyne, Inc. by manufacturing and marketing the ARL through the profitability of each sale and to the additional employees who will be required to supply the ARL to a wide range of users.

The Automatic Radiosonde Launcher will have a significant cost benefit advantage over the present hand-launch technique. This has the potential to benefit not only National Weather Service, Environment Canada, and other national agencies worldwide, but research programs such as the Department of Energy Atmospheric Measurement (DOE ARM) program. Thus an automatic launcher of moderate cost, which will be developed in Phase $\Pi$, will have an extensive market, both nationally and internationally.

\section{PHASE II TECHNICAL OBJECTIVES}

The technical objectives of the Phase II program are:

1. Specify, design, and build one fully functional prototype Automatic Radiosonde Launcher (ARL).

2. Generate sufficient engineering documentation to reproduce the design.

3. Perform such testing as necessary to prove the performance of all major subsystems.

4. Demonstrate prototype performance and capabilities.

5. Install prototype at a site where it can be used daily under real-world conditions to prove the effectiveness of the design. 
6. Perform a cost-to-manufacture analysis and gauge marketability.

The prototype Automatic Radiosonde Launcher will have the following features:

1. Capable of launching, automatically without operator intervention, eight (8) radiosondes without reloading.

2. A shelter to protect the system, stored radiosondes and balloons from the elements with a computer-controlled roof hatch for balloon egress.

3. Certified for helium only (no hydrogen).

4. Automatic system for wetting water activated batteries.

5. Launch in up to 30 knot winds.

6. Remote controllable launch scheduling.

7. Interface to ground station for either Loran or GPS radiosondes.

8. Automatic data recording of received data

9. Remote retrieval of recorded (or real time) data

\section{PHASE II WORK PLAN}

\subsection{Introduction}

This work plan follows the same outline as was used in Sections 3 and 5. Section 3 defined the requirements and problems to be solved in general terms to design a successful ARL. Section 5 discussed the work performed in Phase I to address those problems. This section continues by defining the tasks to be performed in Phase II in each of the previously identified areas.

During Phase I, we designed, built and field tested each of the critical components of our radiosonde launcher (with the exception of the shelter) in a 1-shot breadboard model. During Phase II, we intend to complete the process by taking the design from a model to a preproduction prototype. Each of the components listed below will be designed to a prototype specification.

\subsubsection{Radiosondes}

Radiosondes come from different manufacturers in many different sizes and shapes, with different antenna configurations and different battery sizes and locations. To be accepted by the atmospheric sounding community, we feel that the ARL must accommodate the 
widest possible variety of sondes. We will design a system capable of utilizing all of the commonly used radiosonde types with little or no modification to the sondes themselves. To do this, the design must provide sufficient space for antenna clearance and access for automated battery filling and testing.

Most radiosondes are constructed largely of Styrofoam. The Styrofoam is molded to form compartments for the battery and electronics. A thin cardboard shell holds the unit together. Automatic battery activation requires a watertight battery box (see section 7.2.2). The sonde itself requires no modification other than making two small (about $1 / 2$ inch dia.) holes in the cardboard shell to allow access the water inlet and outlet fittings. (Some sondes may require corresponding holes in the Styrofoam, which should not pose any great difficulty.)

Our colleagues at the Meteorological Systems Group of Sippican, Inc. alerted us to a potential problem with the radiosondes when automatic battery activation is used that must also be addressed. One difference between the manual and our automatic battery activation procedure is that, in the automatic method, the sonde is connected to the battery before activation. When done manually, the battery is wetted and tested for full output before it is connected to the sonde. Apparently some microprocessor-based radiosonde electronics do not tolerate a slow-rising input voltage well, and may not function properly when powered in this manner.

Although we have not observed this problem in any of our testing, it is prudent to explore it further in Phase II. Means to keep the sonde disconnected from the battery until it has reached some minimum threshold voltage may be required to guarantee correct operation with existing radiosondes. In our Phase I field tests, this was done by using a mechanical switch in series with the battery. The switch was made to close by the same actuator that disconnects the water fill lines after battery wetting. An alternative would be to design a very simple circuit using a transistor switch that holds the sonde power off until the battery voltage is within specification.

7.1.1.1 Task: Write a specification for sonde requirements to be used in the ARL.

7.1.1.2 Task: List the currently available sondes that can be used with the Visidyne ARL.

7.1.1.3 Task: Determine the need for a switch between the sonde and battery

7.1.1.4 Task: Choose mechanical or transistor switch. Design the switch.

\subsubsection{Radiosonde Batteries}


There are two requirements for the water-activated batteries. They must be stored in a hermetically sealed container, and they must be in a watertight box with quick-disconnect fittings compatible with the auto filling mechanism. To minimize the impact on the sondes, the battery box will be made large enough to hold the battery, but still small enough to fit the compartment in the radiosonde. That is, the compartment in the sonde that once held only the battery must now hold the battery and the shell we place around it. To accomplish this, we intend to use thin wall injection molding to make the battery box. In Phase I, battery boxes were breadboarded by gluing together thin walled rectangular PVC tubing and sheet stock.

For automatic battery filling, we intend to use the technique developed in Phase I. A vacuum pump will be used to pull the water into the battery box, then, after charging, allow the excess water to drain off. This design does a thorough, reliable job of wetting the battery and eliminates the need for any valves or moving parts in the battery box itself.

Different sonde types use batteries with slightly different dimensions and will require their own battery box designs. Ultimately, we hope that a growing installed base of launchers will entice sonde manufacturers to incorporate suitable battery boxes in their radiosonde designs. We expect that a Visidyne partnership in Phase III with Sippican Inc., a leading manufacturer of radiosondes, will assure that the first user customer's can buy sondes and batteries that are packaged for use with the ARL.

\subsubsection{Task: Design battery box.}

\subsubsection{Balloons}

To be filled by the ARL, balloons must be fitted with a quick-release intake valve compatible with the ARL fill system. Different balloons have various neck diameters, so we will design our intake valves to fit all balloon neck sizes, yet still have a common quick-disconnect plug. The breadboard designed and tested in Phase I is easily attached to standard balloons. No changes will be required to the balloons themselves.

A concern with the balloons is that storage and filling at low-temperature may make them more susceptible to failure. To alleviate this, Visidyne proposes that each balloon be covered with a fold-away electric heating blanket during cold weather. The blanket is draped over the deflated balloon when it is loaded by the servicing technician and falls away as the balloon is inflated. 
7.1.3.1 Task: Produce engineering drawings to the balloon intake valve.

7.1.3.2 Task: Locate a vendor capable of producing the balloon pre-heat blankets.

\subsubsection{Flight Train}

The flight train, dereeler and parachute require their own storage area adjacent to each balloon on the launch platform. We will design a system that allows different sizes to fit without interfering with the launching process.

\subsubsection{Antennas}

Design antennas that allow the sonde signal to be received both before release (inside the shelter) and after launch (outside the shelter)

\subsubsection{Shelter}

Design and build a shelter in compliance with national code that will operate under weather conditions typical in North America. A design requiring low maintenance is highly desirable.

\subsubsection{Radiosonde Canister}

Each canister must be designed to accommodate various size radiosondes and their antennas. The canisters will be hermetically sealed after loading to protect the sonde and battery from moisture and heated to keep water used for battery activation from freezing. Each sonde must be held in the proper position for auto battery filling and flex vacuum lines removal. To allow the sonde to be acclimated to the outside ambient environment prior to launch, means will be provided to ventilate the canister with outside ambient air prior to release.

\subsubsection{Operating Environment}

Water for battery activation must be at a moderate temperature, and the lines to the battery must remain clear after filing, also equipment associated with the launcher must be protected from the elements during hatch open and prelaunch standby. We intend to design safeguards into the system to cover the components.

\subsubsection{Ambient Conditions Monitoring}

Prior to launch, outside ambient conditions must be taken into consideration. We will design the necessary monitoring equipment necessary to achieve this goal. Data such as wind velocity, direction, and temperature will be supplied to the main computer, which will determine a go or no-go for launch. 


\subsubsection{Consumables}

Several helium tanks will be required to support the full load of eight balloons. A helium gas manifold will be provided for multiple helium tanks. Sufficient quantities of compressed air and water will also be provided for. Storage of consumables will be designed for easy access for reloading and while also being protected from the elements.

\subsubsection{Site Requirements}

A general site specification will be written which complies with local codes, and takes into account possible rooftop installations, location of power lines, trees and other obstructions. Power requirements and year round access.

\subsubsection{2 $\underline{\text { Safety }}$}

During the design phase we will constantly be monitoring our progress to be sure we are in compliance with U/L Underwriters Laboratories and CSA Canadian Standard Guidelines. Also, safety measures will be designed to protect children and operators from dangerous situations during the launch processes.

\subsubsection{Computer Software}

Software programs will be written and field tested to cover all of the various possibilities that could arise during a launch sequence, and the necessary backup systems required.

\subsubsection{Other Tasks}

Other necessary tasks not covered in the above discussions of specific systems and requirements are listed below.

1. Write a complete functional specification for the system with sufficient detail to allow engineering to proceed.

2. Launcher Mechanical Design. Perform the necessary engineering, design and build the prototype launcher

3. Electrical Design. Design the interface from the control computer to the mechanical systems, and the interface to the radiosonde ground support equipment (e.g., the receiver).

4. Field Testing. Install the prototype system at the Sippican, Inc. facility in Marion, MA. Support testing of the system and evaluate test results. 


\section{OPTIONAL PHASE II COMMITMENT (COST SHARING)}

Visidyne is pleased to include Sippican Inc. as our partner for Phase II, and hopefully, Phase III of this SBIR program. Sippican Inc. is a leader in the manufacturing of radiosondes and radiosonde equipment. Sippican's engineering expertise will help to ensure the technical success of the program. Sippican's marketing skills in serving the atmospheric sounding community give them a knowledge of the market that will be invaluable in translating technical success into commercial success.

A letter of commitment from Sippican to Visidyne that seals the relationship can be found in Appendix A. A detailed cost proposal for Sippican's contribution-in-kind of $\$ 152,200$ is given in Appendix B.

During the Phase I effort, Visidyne has introduced our automatic radiosonde launcher to a number of people and organizations. While not all were able to participate in cost sharing, their interest in our technology is noteworthy. Appendix $\mathrm{C}$ contains a letter from Ed Murphy of the Air Force Research Laboratory that expresses AFRL's interest in our program. Appendix D is a letter from Eric Frische of Space Data Corporation. Space Data is in developing a commercial venture that will use balloon-borne equipment similar to radiosondes. The anticipate needing thirty to seventy launchers by 2001 , a significant market above and beyond the atmospheric sounding community. 